\title{
PENGARUH LATIHAN LOMPAT GAWANG DALAM MENINGKATKAN TINGGI LOMPATAN SPIKE PADA PERMAINAN BOLA VOLI SISWA EKSTRAKURIKULER DI MAN 2 KOTA BENGKULU
}

\author{
Amirul Shodiq \\ Program Studi Pendidikan Jasmani FKIP Universitas Bengkulu \\ Email : amirulshodiq327@gmail.com \\ Tono Sugihartono \\ Universitas Bengkulu \\ Ari Sutisyana \\ Universitas Bengkulu
}

\begin{abstract}
Abstrak
Penelitian ini bertujuan untuk mengetahui pengaruh latihan lompat gawang terhadap tinggi lompatan spike pada permainan bola voli siswa ekstrakurikuler di MAN 2 Kota Bengkulu. Metode yang digunakan adalah metode penelitian eksperimen dengan desain quasi eksperimen (eksperimen semu). Hasil penelitian menunjukan bahwa selisih pretest siswa setelah mengikuti program latihan lompat gawang di atas lapangan sebanyak 16 kali pertemuan dapat menunjukan peningkatan terhadap tinggi lompatan spike siswa. Dengan populasi 30 siswa dan sampel 30 siswa (total sampling). Instrument penelitian ini berupa tes lompatan spike untuk mengetahui tinggi lompatan spike. Teknik analisis data menggunakan uji-t.hasil. Dari hasil penelitian di peroleh $t_{\text {hitung }}=10,321$ jika di bandingkan dengan nilai $t_{\text {tabel }}=1,696$. Maka nilai $t_{\text {hitung }}>t_{\text {tabel }}$ ini berarti ada pengaruh dari latihan lompat gawang terhadap tinggi lompatan spike siswa di MAN 2 Kota Bengkulu.
\end{abstract}

Kata Kunci : Lompat Gawang, tinggi lompatan spike.

\begin{abstract}
This study aims to determine the effect of goal-jump training on high jump spikes on extracurricular volleyball games in MAN 2 City of Bengkulu. The method used is an experimental research method with a quasi-experimental design (quasi-experimental). The results of the study showed that the pretest difference of students after joining the goal-jumping training program on the field as many as 16 meetings can show an increase in the height of the student's jump spike. With a population of 30 students and a sample of 30 students (total sampling). The research instrument was a jump spike test to determine the height of the jump spike. The data analysis technique uses the $t$-test results. From the results of the study obtained tcount $=10,321$ if compared with the value $t$ table $=1,696$. Then the value of tcount $>t$ table means that there is an effect of the goal jump training on the high jumps of student spikes in MAN 2 City of Bengkulu.
\end{abstract}

Keywords: Jump goal, high jump spike. 


\section{PENDAHULUAN}

Dalam (Undang-undang nomor 3 tahun2005) tentang Sistem Keolahragaan Nasional menyatakan bahwa : Keolahragaan nasional bertujuan memelihara dan meningkatkan kesehatan dan kebugaran, prestasi, kualitas manusia. Untuk meningkatkan sumber daya manusia, maka pembinaaan prestasi olahraga perlu makin di gerakan melalui perencanaan dan pelaksanaan yang mantap serta di laksanakan secara terpadu dan merata di seluruh tanah air. Hal ini bukan saja di lakukan oleh pemerintah, akan tetapi juga perlu di dukung oleh berbagai pihak.

Menurut (Witono Hidayat,2017) Olahraga merupakan salah satu aspek pembangunan manusia yang tidak kalah pentingnya di bandingkan pembangunan lainnya yang merupakan hal pencapaian dan pembangunan indonesia. Disadari sepenuhnya bahwa melalui olahraga akan dapat meningkatkan kesegaran jasmani dan rohani bangsa indonesia sehingga menumbuhkan rasa sportivitas. Untuk mendapatkan sumber daya manusia yang cerdas dan berkualitas tersebut perlu memiliki kesegaran jasmani dan rohani yang baik dan berkpribadian serta memiliki rasa kebanggaan nasional. Hal ini di karenakan pembangunan olahraga yang mengarah pada peningkatan kualitas sumber daya manusia menuju tercapainya manusia Indonesia yang cerdas.

Permainan Bola Voli adalah permainan lempar bola dari tim satu ke tim lawan dan begitupun untuk tim lawan juga harus melempar bola yang datang lewat net ke tim lawan (Pardijono, 2011:1). Lompat gawang adalah latihan ini berfungsi untuk membina kekuatan tungkai, dan kecepatan gerak yang di butuhkan dalam permainan. gawang di buat dengan berbagai ukuran antara lain $10,20,30,40,50,60,70 \mathrm{~cm}$. alat ini berfungsi sebagai rintangan, tantangan agar pemain terpacu untuk mengatasinya.

Latihan lompat gawang sangat di perlukan dalam cabang olahraga bola voli, yaitu apabila memiliki power tungkai yang baik di harapkan dapat melakukan jumping pada saat penyerangan (smash), pertahanan (block), ataupun servis dengan baik. Latihan dengan menggunakan kedua kaki lebih mengurangi beban yang di tahan, namun untuk meningkatkan intensitas, loncatan dengan satu kaki. Loncatan berulang-ulang lompat gawang merupakan latihan yang sangat berguna untuk cabang olahraga bola voli. Menurut (Pardijono, DKK: 2011) Spike adalah pukulan yang utama dalam olahraga bola voli untuk menyerang dan mencapai kemenangan dalam melakukan spike di perlukan jangkauan dan lompatan yang tinggi juga di pengaruhi otot yang mendukung

\section{METODE}

Penelitian ini berjenis penelitian eksperimen. Penelitian eksperimen adalah penelitian yang di lakukan untuk mengetahui akibat yang di timbulkan dari suatu perlakuan ang diberikan secara sengaja oleh peneliti. Penelitian ini di bagi menjadi 3 tahapan yakni pretest, pemberian perlakuan (treatment), dan post test. Desain yang di gunakan dalam penelitian ini adalah one group pretest-posttest design. Dalam design ini tidak menggunakan kelompok kontrol dan subjek tidak di tempatkan secara acak.

Sesuai dengan permasalahan yang dikaji dalam penelitian ini, maka ditetapkan siswa ekstrakurikuler di MAN 2 Kota Bengkulu. sebagai tempat penelitian dengan jumlah siswa 30 siswa. 
Pujianto dan Insanistyo (2017:71) menjelaskan bahwa pengumpulan data adalah proses pengumpulan informasi melalui intrumen penelitian yang telah disusun atau dipakai oleh peneliti. Menurut Sugiyono (2010:308) teknik pengumpulan data merupakan langkah yang paling utama dalam penelitian, Karena tujuan dari penelitian adalah mendapatkan data.Teknik pengumpulan data dalam Penelitian Tiandakan Kelas ini dilakukan dengan cara tes dan observasi.

1. Tes : dipergunakan untuk unjuk kerja memperoleh data siswa tentang gerakan lari jarak 60 meter.

2. Observasi : digunakan untuk mengetahui sikap siswa selama pembelajaran lari jarak 60 meter berlangsung.

\section{HASIL DAN PEMBAHASAN}

Pelaksanaan dalam penelitian ini dilakukan di MAN 2 kota bengkulu Tujuan dalam pelaksanaan penelitian ini adalah untuk meningkatkan tinggi lompatan spike siswa ekstrakurikuler di MAN 2 kota bengkulu. Sampel dalam penelitian ini siswa MAN 2 Kota Bengkulu. Sampel diharuskan untuk mengikuti tes awal terlebih dahulu (prestest) yang bertujuan untuk mengetahui kemampuan awal lompatan spike. Pada saat melakukan tes kemampuan lompatan spike peserta diberikan kesempatan sebanyak 3 kali untuk mencari hasil yang terbaik. Setelah melakukan pretest kemudian seluruh siswa mengikuti program latihan lompat gawang yang merupakan bagian dari penelitian tersebut pada hari yang sudah dijadwalkan.

$$
\begin{aligned}
& \text { Latihan yang di laksanakan selama } 16 \\
& \text { kali pertemuan terbukti berhasil } \\
& \text { memberikan pengaruh terhadap }
\end{aligned}
$$

peningkatan tinggi lompatan spike pada permainan bola voli siswa MAN 2 Kota Bengkulu. Seperti yang di katakan Apta dan Febi, (2105:47) latihan adalah aktifitas untuk meningkatkan kualitas fungsi sistem organ tubuh manusia sehingga mempermudah atlet dalam penyempurnaan geraknya dan latihan proses dimana seseorang atlet dipersiapkan untuk peforma tertinggi (Bompa dan Gregory, 2009:2). Kelebihan dari latihan ini adalah ketika atlet loncat di atas lapangan ketika atlet ingin menolak atau meloncat maka kaki atlet tersebut akan berada diatas lapangan, sehingga menjadi beban ketika atlet meloncat. Dan ketika atlet loncat di tempat yang datar maka tinggi loncatan atlet tersebut akan bertambah. Dalam memberikan program latihan lompat gawang memberikan latihan dengan berbagai macam variasi, yang bertujuan dapat berlatih dengan gembira dan tidak mengalami kejenuhan ketika latihan serta membuat latihan menjadi tidak menonton.

Dari hasil penelitian menunjukkan bahwa selisih mean antara pretest dan posttest siswa setelah mengikuti program latihan lompat gawang di sebanyak 16 kali pertemuan dapat menunjukkan peningkatan terhadap tinggi lompatan spike pada permainan bola voli siswa. Hasil ratarata tersebut dengan waktu latihan yang relatif pendek hanya dapat menyebabkan terjadinya perubahan akibat latihan yang bersifat tetap dan tidak bersifat sementara.

Dan dari hasil t hitung sebesar 10, 321 lebih > dari t tabel 1.699 Maka data hasil pretest dan posttest di nyatakan signifikan. Dengan demikian hipotesis yang berbunyi “ Ada pengaruh latihan gawang di atas lapangan terhadap tinggi lompatan spike pada permainan bola voli siswa di MAN 2 
Kota Bengkulu", diterima. Dengan demikian dapat disimpulkan bahwa penelitian yang telah dilakukan dengan pemberian latihan lompat gawang di atas lapangan terbukti dapat meningkatkan tinggi lompatan spike siswa di MAN 2 Kota Bengkulu.

\section{PENUTUP}

\section{Simpulan}

Berdasarkan hasil penelitian di atas dapat di simpulkan latihan lompat gawang berpengaruh terhadap peningkatan tinggi lompatan spike pada permainan bola voli siswa di MAN 2 Kota Bengkulu. Peningkatan lompat gawang terlihat pada perbandingan perubahan rata-rata pretest dan posttest. Dari data yang sudah diperoleh, hasil pretest sebesar 2,86 dan hasil rat-rata posttest sebesar 29 dengan selisih 2,31.

Hasil penelitian menunjukkan bahwa selisih mean antara pretest siswa setelah mengikuti program latihan lompat gawang di atas lapangan sebanyak 16 kali pertemuan dapat menunjukkan peningkatan terhadap tinggi lompatan spike siswa.

Dan dari hasil t hitung sebesar 10, 321 lebih > dari t tabel 1,699. Maka data hasil pretest dan posttest di nyatakan signifikan. Dengan demikian hipotesis yang berbunyi “ Ada pengaruh latihan gawang terhadap tinggi lompatan spike pada permainan bola voli siswa di MAN 2 Kota Bengkulu", diterima.

\section{Saran-saran}

1. Bagi guru atau pelatih untuk memberikan latihan yang lebih bervariasi lagi selagi upaya untuk mengurangi kejenuhan latihan.
2. Sebaiknya siswa senantiasa meningkatkan latihan lompat gawang di pasir, untuk mencapai prestasi yang lebih baik.

3. Bagi peneliti yang ingin melanjutkan penelitian ini agar dapat menjadikan penelitian ini sebagai bahan informasi dan penelitian dengan populasi atau sampel yang berbeda dan dalam jumlah yang lebih banyak.

\section{DAFTAR PUSTAKA}

Broto, Danang Pujo 2015. Pengaruh Latihan Plyometrics Terhadap Power Otot Tungkai Atlet Remaja Bola Voli. Jurnal motion VI(2):174185.

Chu, D.A dan Myer G Gregory. 1940. Periodazition : Theory and Methotology of Training. Human Kinetics (Advantage Consignment).

Edwan, Ari, dan Bogy. 2017. "Pengaruh Metode Latihan Plyometric Terhadap Kemampuan Jumping Smash Bola Voli Siswa Ekstrakurikuler SMPN 1 Bermani Ilir Kabupaten Kepahiang" Jurnal Kinestetik, Vol. 1 (1).

Harsono. 2015. Kepelatihan Olahraga. Bandung: PT Remaja Rosdakarya.

Hidayat, Taufik. 2011. Bola Voli. Jakarta timur: Rajawali press.

Hidayat, Witono. 2017. Olahraga Pilihan

Bola Voli. Jakarta Timur:

Perpustakan Nasional RI.

Lumintuarso, Ria. 2013. Teori Kepelatihan Olahraga.Jakarta:Lankor. 
Miylsidayu, Apta dan Febi Kurniawan. 2015. Ilmu Kepelatihan Dasar. Bandung: Alfabeta.

Pardijono. 2011. Olahraga Bola Voli. Jakarta Barat: Unesa University Press.

Sugiyono. 2006. Metode Penelitian Kuantitatif Kualitatif dan $R \& D$. Bandung: Alfabeta. 2010. Metode Penelitian
Pendidikan. Bandung: Alfabeta.

Widiastuti. 2011. Tes dan Pengukuran Olahraga. Jakarta Timur: PT Bumi Timur Jaya.

Yunus. 1992. Permainan Bola Voli. Jakarta

Barat: Perpustakan Nasional RI. 